\title{
Mães que Perderam Filhos: uma Leitura Psicanalítica do Filme Rabbit Hole
}

Mothers who Have Lost their Children: a Psychoanalytic Reading of the Film "Rabbit Hole"

Madres que Perdieron Hijos: una Lectura Psicoanalítica de la Película "Rabbit Hole"

Maria Virginia Filomena Cremasco, Dhyone Schinemann \& Susana de Oliveira Pimenta Universidade Federal do Paraná

http://dx.doi.org/10.1590/1982-3703002152013 
Resumo: Para compreender e tratar dos casos de mães que perdem filhos - consensuada enquanto a dor sem nome, sem fim e sem tamanho -, emerge a necessidade de retomar conceitos fundamentais desde o princípio da obra freudiana. O objetivo do trabalho foi lançar luz aos conceitos de luto e melancolia para compreender o sofrimento da mãe diante da perda do filho. O método utilizado foi a análise do filme Rabbit Hole, que retrata a história de um casal que perde um filho. Para enriquecer o trabalho, foram utilizadas vinhetas de entrevistas que realizamos com mães que perderam filhos. Os resultados revelaram o conceito de identificação narcísica enquanto fundamental para compreender a questão posta. Existe a hipótese de que no filme a identificação tenha sido estabelecida com o agressor, o que impossibilita o trabalho de luto. Como conclusão, pontuamos que a perda do filho abre uma grande ferida narcísica que afunda as mães em estados melancólicos. A psicanálise pode conceder um lugar de sofrimento para a mãe que perde o filho sem, contudo, deixar que ela recaia completamente no lugar de vítima, visando que se faça um "giro" da morte em direção à vida.

Palavras-chave: Luto. Melancolia. Psicanálise. Identificação narcísica.

Abstract: To understand and treat cases of mothers who lose their children - known as the nameless, endless and immeasurable pain - emerges the need to return to Freudian fundamental concepts, from the beginning of his work. The objective of the present study was to shed light on the concepts of mourning and melancholia to understand a mother's suffering before the loss of her child. The film "Rabbit Hole", which tells the story of a couple who loses a child, was used as a method of analysis. Also, vignettes from interviews made with mothers who have lost their children were used in order to complement the article. The results revealed that the concept of narcissistic identification is essential for the understanding of the question posed. In the film, there is the assumption that the mother establishes identification with the aggressor, which makes the elaboration of mourning impossible. As a conclusion, it seems that the loss of a child opens a major narcissistic wound that sinks mothers into severe melancholy. Psychoanalysis can provide a place of suffering to mothers that have lost their children, but yet trying not to let them fall completely in the place of the victims, in order to "make a spin" from death towards life.

Keywords: Grief. Melancholy. Psychoanalysis. Narcissistic identification.

Resumen: Para conocer $y$ tratar los casos de madres que han perdido a sus hijos - consensuada como el dolor sin nombre, sin fin y sin tamaño - surge la necesidad de retomar los conceptos fundamentales desde el inicio de la obra de Freud. El objetivo fue aclarar los conceptos de duelo y melancolía para entender el sufrimiento de la madre por la pérdida de su hijo. El método utilizado fue el análisis de la película "Rabbit Hole", que cuenta la historia de una pareja que pierde a un hijo. Para enriquecer el trabajo, se utilizaron viñetas de entrevistas que realizamos con madres que perdieron a sus hijos. Los resultados revelaron el concepto de identificación narcisista como central para la comprensión de la cuestión planteada. Existe la hipótesis de que en la película la identificación se haya establecido con el agresor, lo que hace imposible el trabajo de duelo. En conclusión, parece que la pérdida de un hijo abre una herida narcisista que conduce a las madres en dirección a la melancólica severa. El psicoanálisis puede proporcionar un lugar de sufrimiento para la madre que perdió a su hijo, pero impidiendo que asuma completamente el lugar de la víctima, con el fin de hacer un "giro" de la muerte hacia la vida.

Palabras-clave: Duelo. Melancolía. Psicoanálisis. Identificación narcisista.

\section{Introdução}

A utilização de filmes em trabalhos científicos proporciona a ilustração de questões que se colocam na clínica psicanalítica, contribuindo para uma ampliação de debate que pode colaborar com a compreensão e o compartilhamento do que se coloca como enigmático no trabalho do psicanalista. Partindo disso, o presente trabalho tem como objetivo realizar uma leitura psicanalítica do filme intitulado Rabbit Hole (Estados Unidos, 2010), de John Cameron 
1 Desde 2010, uma das autoras do trabalho participa de um grupo de apoio a enlutados, realizando e orientando pesquisas que adentram no campo das perdas e suas reações, nos cursos de graduação e pós-graduação do departamento ao qual pertence.

2 Termo contemporaneamente autoinstituído por aqueles que perderam entes queridos e que estão sofrendo a dor por sua perda.

3 O presente artigo é resultado de um projeto de pesquisa aprovado pelo Comitê de Ética em Pesquisa do Setor de Ciências da Saúde da Universidade Federal do Paraná (registro CEP/SD: 1297.222 .11 .12 de 24 de fevereiro de 2012). O comitê autorizou a utilização de dados empíricos, coletados por intermédio de entrevistas e atendimento de mães que perderam filhos, uma vez que se sigam os termos acordados e os preceitos éticos devidamente estabelecidos.
Mitchell, dando enfoque na experiência da mãe que perde um filho por óbito.

O artigo propõe a leitura de alguns aspectos observados no filme que possibilitam um retorno a conceitos básicos da obra de Sigmund Freud, com o objetivo de lançar luz às questões do luto e da melancolia. Elegemos também um texto da obra de Sándor Ferenczi, psicanalista contemporâneo de Freud, que auxiliará no aprofundamento de um dos elementos presentes na trama: o trauma psíquico.

O presente artigo é fruto de uma trajetória de estudos ${ }^{1}$ que trata da questão da perda. A perda de entes queridos, especialmente dos pais que perdem seus filhos, torna evidente a vulnerabilidade do ser humano frente ao desaparecimento dos objetos de amor, nos quais são investidos os mais intensos sentimentos. Dados de nossa experiência clínica com pacientes enlutados ${ }^{2}$ mostram que a perda de um ente querido pode ser devastadora, sobretudo para a mãe que perde um filho, como retrata o filme Rabbit Hole.

O filme conta a história de um casal que perdeu um filho de quatro anos há aproximadamente oito meses. Diante de um sofrimento intenso de perda, que faz despertar diversas questões em cada personagem do filme, foi possível fazer um recorte de algumas questões essenciais da experiência de um enlutado com base em nosso trabalho anterior com a clínica. A partir da análise do filme chegamos a unidades conceituais que consideramos fundamentais no manejo com aqueles que padecem de sofrimento intenso devido à perda. Optamos por apresentá-las aqui divididas em tópicos, que serão desenvolvidos ao longo do trabalho. São eles:

a) A dor da mãe ao deparar-se com as lembranças do filho;

b) A dificuldade de relacionamento do casal que perdeu o filho;

c) Sentimento de culpa pela morte do filho;

d) Mudança na atribuição de sentido às coisas da vida após a experiência da perda;

e) Intolerância à "felicidade" alheia e busca por isolamento;

f) Identificação da mãe com o agressor.
O referencial teórico psicanalítico dará subsídios para uma interpretação do filme em torno dos pontos acima citados.

Essas unidades retiradas do filme serão analisadas e interpretadas por intermédio das obras de Freud e de Férenczi, reavivadas em prol de contribuir para a compreensão clínica da experiência do sujeito que perde o ente amado. $\mathrm{O}$ trabalho possibilitará que as cenas que retratam a vida após a perda de um filho para a morte possam ser percebidas sob um ângulo mais aprofundado, que auxilie o constante processo de construção da clínica psicanalítica. Para discutir a questão referente à identificação com o agressor (tópico f), recorreremos à Férenczi (1966).

Em alguns momentos do trabalho faremos uso de vinhetas discursivas ${ }^{3}$, ilustrações de falas provenientes de nossa experiência clínica, com o intuito de enriquecer a discussão dos pontos apresentados.

\section{Análise do filme}

Rabbit Hole (2010) conta a história do casal Becca e Howie Corbett a partir do momento em que perdem seu filho de quatro anos, Danny. O filme retrata a mesma história da premiada peça, de mesmo nome, criada pelo autor americano David Lindsay-Abaire, encenada pela primeira vez em 2005. O filme mostra os desdobramentos decorrentes de uma perda tão significativa na vida dos pais, quando não têm mais a presença de seu filho. O filho é atropelado por um adolescente (Jason), que dirigia em velocidade um pouco acima do permitido na rua onde Becca, Howie e Danny moravam; e atropelou a criança no momento em que ela corria pela rua atrás do cachorro (Taz). Passados oito meses do falecimento do filho, Becca parece não mais suportar ficar o dia todo em casa, em contato com todas as lembranças do filho, pois não trabalha e não tem prazer em estar com outras pessoas.

No filme são retratados dois eventos da vida de Becca que podem ser considerados fatores complicadores. O primeiro deles refere-se ao fato de que a irmã solteira engravida no período em que a personagem ainda experimenta a dor por sua perda de modo bastante intenso. Esse acontecimento parece ter uma grande 
4 De acordo com o professor mestre Renato Las Casas (UFMG, 2013), do Observatório Astronômico Frei Rosário, da Universidade Federal de Minas Gerais, buracos de minhoca são "tubos de espaço-tempo" que interligam diferentes regiões do espaço e do tempo. Esses tubos proporcionariam viagens no espaço-tempo por intermédio da entrada por uma de suas extremidades e da saída imediata pela outra extremidade em local e/ou tempo diferentes.

5 Todos os nomes utilizados são fictícios com o objetivo de proteger a identidade das entrevistadas. influência na personagem. O segundo fator refere-se à mãe de Becca que, como também perdeu um filho há 11 anos (irmão de Becca), acaba por ser invasiva ao compartilhar e comparar sua experiência com a da filha. As comparações parecem ser agressivas para Becca por representarem uma minimização da legitimidade de sua dor.

Becca e Howie frequentam um grupo de apoio a enlutados. Contudo, Becca não se identifica com os demais integrantes. Incomoda-se com o fato de serem adeptos de religiões e de estarem no grupo há muito tempo, o que parece gerar na personagem uma sensação de impossibilidade de superação do sofrimento. Então, acaba por se afastar definitivamente do grupo. Em dado momento, reencontra Jason, o jovem que atropelou seu filho, e tem um súbito impulso de ir atrás dele. Timidamente, encontra-se com ele para conversar e eles falam sobre o acontecido. Depois disso, combinam de se ver por diversas vezes. Ao longo dos encontros, Becca parece começar a dar maior importância ao rapaz, parecendo desenvolver por ele um sentimento terno, fazendo questão de agradá-lo, bem como de estar presente em sua vida. Becca parece ter necessidade de estar colada ao agressor de seu filho, visto que é o que restou do evento traumático da perda.

Enquanto Becca reage à perda com essa necessidade de aproximação de Jason, seu marido, de quem se distancia drasticamente, continua a frequentar o grupo de apoio a enlutados. Na ausência da esposa, Howie começa a se encontrar com uma das mães que frequenta o grupo há mais tempo e que fora recentemente abandonada pelo marido. Além disso, em suas horas vagas, Howie gosta de assistir aos vídeos do filho Danny. O fato de Howie buscar reavivar as lembranças do filho quando está em casa é intolerável para Becca, o que ocasiona brigas entre o casal.

No início do filme, vemos que Becca deixa o cachorro Taz na casa de sua mãe, doa a maior parte das coisas do filho e quer vender a casa onde moram, pois sente a presença do filho em todo o lugar. Em contrapartida, Howie não quer se desprender de nada, inclusive permanece andando com a cadeirinha do filho no carro e busca Taz na casa da sogra, trazendo-o de volta para casa após discutir com Becca. Essa discussão é "divisora de águas" e coloca o espectador do filme em dúvida a respeito da possibilidade de o casal se manter unido. Ao final do filme, somos surpreendidos com o fato de que eles se mantêm casados, apesar de todas as diferenças de reação à perda, conseguindo encontrar uma forma de sobreviver ao evento, porém sem reencontrar a felicidade.

O termo rabbit hole (cuja tradução literal seria "toca do coelho") escolhido para intitular o filme faz menção à ideia de wormhole ${ }^{4}$ (buraco da minhoca) da física e à obra Alice no País das Maravilhas, de Charles Lutwidge Dodgson (1865). Na fábula de Alice, a toca do coelho por intermédio da qual ela entra em contato com outra realidade faz crer na possibilidade da existência de realidades paralelas a essa na qual vivemos.

Durante o filme do qual estamos tratando, percebemos menção a essa possibilidade nas conversas entre Becca e Jason, bem como em uma revista em quadrinhos que ele desenvolve. Uma interpretação possível da relação entre a história e o título diz respeito a uma necessidade de Becca e de Jason de acreditar que Danny está vivo e bem em outra realidade. Também podemos observar nas vinhetas a seguir algo semelhante:

\section{Heloísa : "[...] hoje ela é um anjo intercessor, digamos assim, né?, e graças a Deus ela está bem, né?, a gente tem certeza disso". Janaína: "Eu não sei de onde que eu consegui tanta força. Eu não chorei, eu não fiz nada. Entendeu? [...] Com a fé que eu tinha, eu pensei: 'Isso aqui é só o corpo da minha filha, ela já está, né?, com Deus".}

Como podemos perceber, a busca por uma possibilidade paralela de continuidade de existência para o objeto perdido é comumente observada na relação dos enlutados com a espiritualidade e com as religiões. A fim de dar continuidade à discussão de questões relevantes para a compreensão da perda na clínica psicanalítica, passemos à análise dos tópicos retirados da análise do filme e mencionados na introdução do trabalho.

a) A dor da mãe ao deparar-se com as lembranças do filho 
Em seu texto Análise terminável e interminável, Freud (1996a) nos alerta que:

Em estados de crise aguda, a análise é, para todos os fins e intuitos, inutilizável. Todo o interesse do ego é tomado pela realidade penosa, e ele se retrai da análise que está tentando ir além da superfície e revelar as influências do passado. Assim, criar um novo conflito só tornaria o trabalho de análise mais prolongado e mais difícil (Freud, 1996a, p. 248).

Essas considerações acerca da dificuldade de se pensar um tipo de trabalho com as pessoas em estado de crise, tal como as que sofrem a dor da perda de um ente querido, coloca-nos diante do compromisso de pensar a questão do luto enquanto uma situação dessa natureza e nos imputa a reflexão na busca pela compreensão acerca desse fenômeno que, cedo ou tarde, acomete a todos os seres humanos.

Após a perda do objeto, o trabalho de luto tem início e concentra boa parte da libido em seu investimento, o que faz com que a pessoa enlutada se afaste de todas as atitudes consideradas normais da vida. Freud (1996e) ressalta que o afastamento do que antes fazia parte da vida do enlutado deve-se ao período de enlutamento, em que a libido está sendo retirada de suas ligações com o objeto perdido, uma a uma, e que o trabalho acaba quando o investimento libidinal puder ser destinado a um novo objeto. Assim sendo, Freud (1996e) assevera que o trabalho de luto não deve ser considerado como uma condição patológica, julgando "inútil ou mesmo prejudicial qualquer interferência a ele" (Freud, 1996e, p. 249).

Ao assistir o filme, questionamo-nos o que provoca tamanha dor na mãe que perde seu filho (no caso desse filme, na personagem Becca). As considerações trazidas da leitura da obra freudiana apontam que a dor não advém somente da rememoração de fatos envolvendo o filho, mas da impossibilidade de reviver os momentos com o filho que se foi, que é constatada no confronto com as inúmeras lembranças. Podemos inferir, portanto, que o enlutado pode preferir não ter contato com lembranças do ente que se foi como uma forma de recusa a se confrontar com a realidade e de desinvestir do objeto perdido. Na cena em que Howie quase bate o carro e
Becca fica preocupada com o bolo que está no banco traseiro, podemos perceber que a mãe encontra-se ainda muito ligada à ideia do filho vivo, uma vez que fica evidente a preocupação da personagem com o filho, projetado no bolo, já que ele costumava ocupar o lugar no banco traseiro. A necessidade da presença do filho fica evidenciada ao percebermos que Howie continua trafegando com a cadeirinha do filho acoplada no banco de trás.

Mais adiante, Becca resolve desfazer-se das coisas do filho. As lembranças do filho que partiu geralmente são suscitadas por cenários, objetos, situações ou pessoas que servem de referência para o fato insuportável dessa perda que não cessa de fazer-se lembrada. O desfazer-se desses objetos que evocam as memórias do dia a dia com o filho também pode ser entendido como uma tentativa desesperada de desligamento do objeto perdido que seja rápida e eficaz, haja vista a perspectiva de que esse desligamento não ocorrerá sem um longo período de muita dor e sofrimento.

Ao mesmo tempo em que a realidade revela que o objeto amado não existe mais, ela provoca uma grande oposição no enlutado, tendo em vista que, conforme já afirmamos, ninguém abandona de bom grado uma posição libidinal. Para Freud (1996e) é possível que a oposição à realidade da morte seja tão intensa que origine um desvio da realidade, a ponto de a pessoa permanecer apegada ao objeto amado por meio de uma psicose alucinatória (princípio do prazer). Observa que em alguns casos as ordens da realidade vão, aos poucos, podendo ser obedecidas com grande gasto de tempo e de energia catexial sendo que, nesse meio tempo, o objeto perdido continua a existir. Uma a uma, as ligações libidinais com o objeto perdido vão sendo desfeitas, em um processo penoso e de extremo desprazer. Concluído esse processo, o ego encontrar-se-á novamente livre e desinibido.

A história contada pelo filme mostra que, para a mãe que perde o filho, o processo de desligamento do objeto é bastante complexo e, segundo nossa experiência clínica, geralmente impossível. Para Freud (1996b) o filho está diretamente envolvido nas feridas narcísicas da mulher. Ele nasce para satisfazer um desejo 
fálico e legitimar a feminilidade, como ilustra a seguinte vinheta:

Anabela: "Filho é filho, não adianta, pra uma mãe é um... é uma coisa, assim, extraordinária, não tem. É uma coisa visceral... Isso! É de vísceras. É de... é meio que... é a mesma pessoa! Eu sinto como se eu tivesse perdido... não vou dizer a metade de mim porque eu tenho outro filho, mas... mas grande parte de mim... grande, quase tudo".

Como podemos perceber por meio do discurso de Anabela, no trabalho com a clínica psicanalítica do luto e da melancolia é comum no discurso das mães que perdem o filho por óbito a descrição da sensação de sentiremse sem uma parte delas próprias, como se o filho fosse para a mãe uma extensão do seu corpo. É sabido que os pais projetam seus ideais sobre seus filhos, bem como os filhos constroem um ideal para o seu ego com base nas concepções e desejos de seus pais. Por esse motivo, essa ligação é repleta de expectativas, pois os pais projetam muito de si mesmos nos filhos e os filhos respondem a isso de alguma forma. No momento em que ocorre a perda de um filho por óbito, ou seja, quando há o rompimento definitivo dessa relação, podemos compreender por que as mães argumentam que uma parte delas próprias foi perdida.

O lugar que o filho ocupa na vida da mãe vai determinar a reação à sua morte. A experiência clínica mostra que algumas vezes essas mães estabelecem uma "identificação narcísica" com o filho, processo sobre o qual Freud (1996c) discorre em uma de suas conferências introdutórias. Na medida em que o sujeito retira sua libido do objeto perdido, sofre um processo chamado "identificação narcísica", que faz com que o objeto se estabeleça no ego, projetando-se sobre o ego.

Nesse processo, a mãe projeta o objeto perdido sobre si para não ter de se afastar dele. Tratase de um dos mecanismos encontrados na clínica, que não podemos afirmar ser o caso de Becca, por falta de dados e pelo fato de o filme retratar sua perda como ainda relativamente recente. Contudo, percebemos em Becca o uso de um mecanismo aproximado desse para lidar com sua perda, que se refere a uma identificação com Jason, ponto sobre o qual discorreremos mais adiante por intermédio de Férenczi.

Ligada à questão da dor da mãe que perde o filho e tem dificuldades de lidar com o que esse deixa para trás, está a fragilização dos vínculos dessa mãe com familiares e amigos. É bastante comum observarmos a desestruturação das famílias diante da perda de um filho, essencialmente da relação marido e mulher. Trataremos dessa questão a seguir.

b) A dificuldade de relacionamento do casal que perdeu o filho

São evidentes as dificuldades de Becca e Howie em seu relacionamento amoroso após a morte do filho. As reclamações do marido em relação à falta de atividade sexual são persistentes. Com o passar do tempo, sem o contato físico e com constantes divergências em relação à reação de cada um à perda, vai se tornando óbvia a fragilidade do vínculo entre o casal. Essa fragilidade é deflagrada quando Howie passa a buscar respostas aos seus anseios junto à outra pessoa, uma mulher do grupo de apoio a enlutados que sofreu sua perda há oito anos e que acaba de ser abandonada pelo marido.

Imersa em seu sofrimento, Becca parece nem perceber o envolvimento do marido com outra mulher. Com a ausência dele, de forma sigilosa, ela começa a se aproximar do adolescente que atropelou o filho. Gradativamente, percebemos que o casal se afasta das relações familiares e de amizade que mantinha antes para estabelecer novas relações com pessoas diretamente ligadas à sua perda. Nas vinhetas que apresentamos a seguir poderemos ter uma maior compreensão de como isso ocorre na vida dos enlutados:

Olga: "Porque a gente fica... difícil de lidar. Assim, tenho muita dificuldade em socializar com as pessoas, assim. Tenho muita dificuldade. Até mesmo com meu marido". Betânia: "Eu me distanciei de todas as outras pessoas. Eu tava ali quase 30 anos na empresa, aquele mundo de lá eu não quero... as pessoas de lá, canso de ver na rua, atravesso, me escondo. Em mercados, passo do outro lado pra não ver, porque eu me agrupei, me uni com as pessoas que são iguais a mim" [referindo-se a outras pessoas que perderam um filho]. 
Observamos, portanto, que a perda se torna o tema principal e direciona os movimentos da vida. Ainda que tenham se passado muitos meses desde o evento da perda (como no caso de Becca), o registro desse tempo é diferente no inconsciente. Freud (1996h) nos ensina que a temporalidade do inconsciente se diferencia da versão cronológica porque não a reconhece.

Desde que a distância não tem importância para o pensamento - desde que o que fica mais afastado tanto no tempo quanto no espaço pode sem dificuldade ser abrangido num único ato de consciência - assim também o mundo da magia tem um desprezo telepático pela distância espacial e trata as situações passadas como se fossem atuais (Freud, 1996h, p. 96).

O inconsciente não reconhece a cronologia do tempo porque nele não há o registro da finitude. É devido à ausência do registro da finitude que nos lançamos à vida de projetos e fazemos planos de longa data, visto que se considerássemos o tempo todo que o fim pode se dar a qualquer momento não haveria maneira de planejar, construir e organizar a vida como fazemos: como se fôssemos eternos. Entretanto, a morte de um ente querido nos impõe um confronto - que é adiável, mas inevitável - com a finitude (Freud, 1996g). A concretização da finitude é um dos fatores que contribui para que o casal, ainda muito invadido pelo evento da perda e pela dor que isso provoca, não possa estabelecer as relações da mesma maneira que antes. A experiência de perder um objeto de amor pode levar a um receio de amar de novo. Renunciar ao amor que se tem por um objeto é como livrar-se da possibilidade de sofrer com a morte dele.

Outra questão que contribui para a dificuldade de relacionar-se refere-se à diferença nas formas de Becca e Howie vivenciarem a perda. Os desencontros do casal vão se tornando evidentes na medida em que passam a procurar respostas para o mal-estar vivido em casa fora dela.

Diante de tantos desencontros atuais nas relações após o evento da perda do filho e do confronto com a finitude dos objetos, qual a possibilidade de reinaugurar os laços de amor?
No final do filme desponta uma possibilidade para essa reinauguração. Assistimos uma cena bastante interessante que demonstra a forma como o casal procura ver o futuro. Becca questiona o marido sobre o que farão no dia seguinte e ele reponde que poderiam fazer um churrasco em família. Angustiada, ela pergunta: "E depois?" Então, ele responde com outro possível plano. A cena segue com Becca perguntando sobre o depois e com Howie respondendo por várias vezes, com outros planos. Em dado momento da conversa, podemos ver o início de uma mudança. Parece que o tempo já é outro e que já há uma mobilidade, ainda que forçosa. Por fim, Becca questiona Howie: "E então o quê?"; ao que o marido responde: "Eu não sei, alguma coisa surgirá".

A dificuldade de relacionamento do casal perpassa por uma sensação de que a vida nunca mais poderá ter o colorido que tinha antes. Diante da morte de um filho, impõese uma barreira a toda e qualquer sensação de prazer. Nossa experiência mostra que para a mãe que perde o filho, renunciar ao sofrimento eterno por sua perda gera culpa, pois há um entendimento de que a mãe que realmente ama o filho nunca mais será feliz sem ele. Essa falta de permissão para ser feliz e o sentimento de culpa são pontos que discutiremos a seguir.

c) Sentimento de culpa pela morte do filho

Em determinado momento do filme, Howie percebe que o vídeo de Danny brincando que estava armazenado em seu celular foi deletado. Instantaneamente, acusa Becca de tê-lo apagado em sua ânsia por dar fim em todas as coisas que lembram o filho. Diante da acusação, Becca se defende, alegando que talvez tenha apagado o arquivo acidentalmente. Esse fato leva o casal a reviver novamente o acidente que culminou na morte do filho e ambos passam a culpar um ao outro e a si mesmos pelo que aconteceu. Becca deixa claro nessa cena que já haviam passado por outras discussões parecidas, nas quais foram feitas tentativas, sem sucesso, de eleger o grande culpado pelo que aconteceu.

Para Freud (1996i), o sentimento de culpa pela morte de um ente querido deriva do caráter 
ambivalente do sentimento que mantemos por quem amamos. Isso significa que ao mesmo tempo em que amamos, odiamos a mesma pessoa. Esse sentimento de ódio fica relegado ao inconsciente. Essa face negativa do sentimento que, por vezes, conduz a um desejo de morte, também não expresso de maneira consciente, acaba por manifestar-se nos sonhos. Eis uma explicação possível do porquê de sonharmos com a morte de entes queridos.

Vale esclarecer que a expressão de um desejo pela morte de um ente querido nem sempre é atual, pode estar deslocada, remeter a conflitos edípicos antigos da vida do sonhador, tal como o ódio pelos pais. Esse sentimento, a título de exemplo, vem representado nos sonhos em que os pais morrem. O problema é que quando o ente querido morre, a face negativa do sentimento que está no inconsciente acaba satisfeita e isso pode gerar um enorme e ininteligível sentimento de culpa naquele que mais amava o morto.

Como a libido que a mãe investe num filho algumas vezes é de teor narcísico, o desinvestimento objetal diante da morte do filho pode abrir portas para um movimento de identificação narcísica (conforme explanado no item a).

[...] a identificação é uma etapa preliminar da escolha objetal, que é a primeira forma - e uma forma expressa de maneira ambivalente - pela qual o ego escolhe um objeto. O ego deseja incorporar a si esse objeto, e, em conformidade com a fase oral ou canibalista do desenvolvimento libidinal em que se acha, deseja fazer isso devorando-o (Freud, 1996f, p. 255).

O ego faz a identificação com o objeto e o ama com tal intensidade que deseja devorá-lo. São comuns brincadeiras em que os pais se referem a seus bebês como "coisas gostosas que dão vontade de morder". Diante da perda do bebê, a ambivalência empresta ao luto um conteúdo patológico que força à autorrecriminação, "no sentido de que a própria pessoa é culpada pela perda do objeto amado" (Freud, 1996f, p. 283) em função de desejos primitivos em relação ao objeto. Esse tipo de autotortura tem algo de agradável ao sujeito e significa uma forma de presentificar o objeto perdido.
Muitas mães demonstraram sentir culpa em relação à morte de seu filho como podemos observar nas vinhetas apresentadas a seguir:

Betânia: "Tenho o sentimento de culpa e me pergunto sempre: será que se eu não tivesse ido pra outro hospital, se não tivesse talvez outros médicos, quem sabe se eu tivesse levado pra outro não tinha sido diferente (...) Sempre a gente se culpa. Por que eu não vi isso? Por que não vi aquilo?" Janaína: "E... tinha 'um porém': que eu também achava minha culpa. Eu, além de perder, ainda achava que era minha culpa. (...) Mas só que eu punha em mim a culpa: 'Ai, meu Deus, por que que eu fui deixar ela ir trabalhar, ai, meu Deus, por que que...', sabe? Então, aquela culpa me machucava muito! E daí eu falava muito no grupo [de apoio a enlutados] sobre a culpa".

Parece, portanto, ser bastante comum que aqueles que perderam pessoas amadas falem sobre uma culpa aparentemente inexplicável pela morte do objeto amado.

Quando uma esposa perde um marido ou uma filha, a mãe, não é raro acontecer que a sobrevivente fique atormentada por dúvidas atrozes (às quais damos o nome de "autocensuras obsessivas") quanto a se ela própria não poderia ter sido a responsável pela morte desse ente querido através de algum ato de descuido ou negligência. Nenhuma quantidade de lembranças do cuidado que prodigalizou ao sofredor e nenhuma quantidade de reputações objetivas a acusação servem para dar fim ao tormento (Freud, 1996h, p. 73).

Como não podemos expressar o ódio que sentimos pelos entes queridos, os mecanismos de defesa atuam e realizam a projeção dos sentimentos hostis para lugares e objetos em que esses sentimentos podem ser descontados, como no trânsito, nos estrangeiros, naqueles que nos prestam serviços etc. Contudo, ainda que essa dinâmica de deixar a hostilidade de fora seja bem-sucedida, o sobrevivente apresenta características de castigo e remorso. Imerso em uma civilização repleta de culpa e de temores, o sujeito se submete a renúncias e restrições em função de sua culpa.

Para Freud (1996c), quando perdemos alguém que amamos é provável que a parte ambivalente que desejava essa morte nos torne culpados e 
merecedores de punição. Diante da perda, os sentimentos hostis que conservávamos por essa pessoa estão agora sanados. Toda raiva, medo ou ódio que tínhamos está derrotado. Somos, portanto, vencedores. Todavia, passamos a conviver com uma grande culpa que retorna para nosso eu, tornando-nos fadados à ruína por esse êxito.

Dessa forma, o enlutado pode se manter insatisfeito e infeliz, passando a contar com a possibilidade de punição como forma de redimir a culpa, como podem, por exemplo, ser encarados o adoecimento ou a depressão.

A dor sentida pela mãe que perde o filho parece produzir modificações em sua visão e no sentido que atribui às coisas. No filme, há uma cena em que Becca vai ao grupo de apoio a enlutados e escuta um casal dizer que Deus levou seu filho porque estava precisando de anjos no céu. Becca fica furiosa com o que escuta e questiona por que Deus haveria de levar o filho deles, ao invés de tão somente assoprar e criar um novo anjo, tendo em vista que é onipotente. Parece que para Becca não há possibilidade de uso de qualquer mecanismo para fantasiar a realidade do que aconteceu. Muitas mães relatam sentimentos de revolta com seu deus e/ou com a natureza. Além disso, relatam a insatisfação por algo tão penoso, como a morte de um filho, ter acometido justamente a sua vida e não a vida de outra pessoa.

Sara: "Você perde a sua... em primeiro lugar, a sua fé em Deus. Em segundo lugar, você perde o chão, você perde parte da sua vida". Betânia: "E todos os dias... as pessoas vão embora... muitas, muitas e muitas, mas apesar disso a gente não entende, sabe?, não consegue entender por que o meu? Por que o meu? Por que o meu? Pode ser com o vizinho, mas não pode ser o meu, mas o vizinho vai passar pela mesma dor que eu. Então é assim".

Essas falas nos mostram como a morte de um filho parece inserir na vida dessas mães uma revisão de valores. As mães fazem parte de um grupo de apoio a enlutados (Amigos Solidários na Dor do Luto, do qual também participamos, observando) e, nesse contexto, é comum ouvirmos as mães que perderam filhos dizerem que não veem mais sentido em assistir televisão, comprar roupas novas, passear no shopping ou conversar sobre a vida alheia. Elas relatam que gostam muito de conversar sobre o filho falecido, mas ninguém quer ouvir disso. Observamos que o que mais as interessa em termos de programa de televisão são os noticiários que trazem notícias diárias sobre as tragédias ocorridas. Vamos abordar mais detalhadamente, no próximo tópico, a questão da revisão de valores.

d) Mudança na atribuição de sentido às coisas da vida após a experiência da perda

Em diversas cenas do filme, a personagem Becca aparece com um posicionamento diante das coisas que advêm de sua experiência de perda. Na cena em que ela aparece na reunião do grupo de apoio a enlutados fica evidente a discordância que ela apresenta em relação à forma como a morte é significada pelos demais integrantes do grupo. Ali, ela mostra que não há o que possa explicar ou justificar o que ocorreu com seu filho e passa a não mais poder tolerar as explicações, a "verdade" das outras pessoas. Nas cenas em que a mãe dela tenta compartilhar sua experiência de perda com a filha, visando reconfortá-la, Becca rechaça o discurso da mãe como se essa não pudesse compreender sua dor, por se tratar, em sua percepção, de algo diferente do que a mãe passou, tendo em vista que Danny era pequeno e inocente, enquanto seu falecido irmão era adulto e sempre tinha atitudes inconsequentes.

Freud (1996e) nos ensina que uma característica importante do melancólico é o fato de ele julgar possuir uma visão mais próxima da verdade do que as pessoas que não são melancólicas. O melancólico é capaz de reconhecer seu egoísmo, desonestidade, carência de independência, enfim, suas fraquezas. Isso ocorre porque ele perde a possibilidade de continuar vivendo sob uma égide de ilusões. Freud (1996e) questiona: "por que um homem precisa adoecer para ter acesso a uma verdade dessa espécie"? (Freud, 1996e, p. 252).

Por intermédio dessa compreensão, podemos entender por que Becca não aceita que as pessoas atribuam sentidos sobrenaturais para a morte de seu filho. Se ela aceitasse as explicações acolhedoras que lhe são ofertadas 
isso poderia retirá-la de sua verdade crua e dolorosa da vida, como descrita no item anterior. Parece-nos que o traço melancólico detentor de uma verdade própria e desmentida da vida se impõe a Becca.

É diante dessa compreensão que a vida perde seu colorido e tudo parece ficar mais "cru". Quem perdeu alguém e recaiu na melancolia não tem mais o álibi das ilusões e pode chegar a sentir imenso desprazer em festividades e datas comemorativas, bem como não reconhecer possibilidade de satisfação em atividades que envolvam compras, eventos que são socialmente instituídos como fontes de prazer. A culpa já explorada anteriormente também se associa a essa desvalorização do prazer. As falas de mães parecem retratar esse panorama, de modo que podemos perceber que o luto pode representar uma ruptura com algumas ideias e concepções ou até mesmo atividades que antes da morte de um filho pareciam fazer bastante sentido.

Olga: "Meu mundo caiu, foi horrível. Me senti muito, assim, não dá nem pra descrever. (...) Tudo vem à tona. Tudo vai, assim, teus sonhos, as coisas que você imaginava passar com a tua filha, tudo isso vai pro ralo, né?, de uma hora pra outra". Eliza: "O desespero era tão grande, a dor era tão grande que eu não via mais o mundo lá fora. Eu não sentia mais que tinha uma vida. (...) Por mais que eu tenha mais dois filhos era como se eu não tivesse mais ninguém, era como se eu estivesse perdida no universo. (...) E eu não me importo mais com nada, assim, de vaidade, de ter coisas. A gente pensava em ter uma casa na praia; hoje a gente já não quer mais. A gente não quer ter além daquilo que a gente tem, o básico, porque nada mais nos alegra".

Podemos, a partir desses trechos, observar que algo que costuma ocorrer nesse processo diz respeito a uma intolerância com quase todas as pessoas que, segundo a visão melancólica, insistem em fechar os olhos para o advento da morte e continuam sorrindo, comprando e dando festas sem perceber que a qualquer momento isso pode as acometer.

Para Freud (1996d) a fixação afetiva em algo que é passado que acontece no luto, envolve a mais completa alienação do presente e do futuro. Permanecendo completamente absorvida psiquicamente no passado, a pessoa em luto patológico pode se isolar dos planos e projetos que podem tirá-la desta fixação. Essa questão nos conduz ao tópico que segue.

e) Intolerância à "felicidade" alheia e busca por isolamento

As principais cenas que demonstram uma intolerância por parte de Becca à felicidade alheia se referem à repentina gravidez de sua irmã solteira. Há uma cena em que Becca, que aparentemente sempre cuidou de sua irmã como uma filha, vai à delegacia retirar a irmã da prisão e em seguida a acolhe, alimenta e passa um sermão dizendo a ela que deixe de ser criança. Posteriormente, quando Becca descobre que a irmã está grávida, faz uma série de atos que demostram seu incômodo com o fato. Parece que, devido à perda do filho, Becca não pode entrar em contato com a satisfação da irmã em ser mãe. Em outra cena, a protagonista também se mostra incomodada quando na biblioteca vê a cena de uma mãe lendo descontraidamente para a filha pequena.

Analisando essa situação pela óptica da condição melancólica, Freud (1996e) compara a melancolia a uma ferida aberta que atrai para si todas as energias catexiais. Essa ferida esvazia o ego até que fique totalmente empobrecido, daí a intolerância a qualquer imagem do outro satisfeito. Freud (1996f) explica que ao nos depararmos com a morte do ente querido sofremos de uma paralisia pelo pensamento de quem poderá substituir o objeto perdido.

Os pensamentos giram em torno do morto e do tema da morte o tempo todo. Então, como Becca poderia lidar com as pessoas que continuam a viver sua vida e a dar festas, conseguindo manter distância do contato com a finitude? Uma possibilidade é a busca pelo isolamento. Manter-se afastada do convívio com as pessoas e com a "felicidade" alheia é resposta à dificuldade de lidar com essa alegria que passa a pertencer somente ao outro, não mais à mãe que perde o filho.

A questão do isolamento aparece na relação de Becca com a família, com quem se mostra sempre refratária e também, como vimos, com o marido. Além disso, ela rejeita de todo a 
ideia de se reunir com os vizinhos para jantar e não tolera os integrantes do grupo de apoio a enlutados.

Parece que Becca não consegue mais amar ninguém após a perda do filho. Tudo o que não diz respeito a ele é vivido com insegurança e incômodo. Isso pode ser explicado, como vimos, pelo próprio processo de luto, conforme descrito por Freud (1996e). Porém, caso se trate de uma melancolia, essa resolução parece nunca ocorrer. Vemos nas falas das mães uma grande preocupação com o isolamento, tanto no que diz respeito a elas mesmas isolando-se do convívio social ou familiar, quanto no fato de as pessoas afastarem-se delas.

Ivana: "E que tinha outras pessoas, que eu não tava nesse mundo sofrendo sozinha, porque eu me sentia assim, porque amigos se distanciaram. Ou eu fui me distanciando e distanciando eles, né? Eu tinha dias que não atendia nem o telefone. Então, é lógico que quem não é visto não é nem lembrado, né? E eu nem me preocupava em procurar alguém, nada". Eliza: "E os amigos antigos, esses ficaram pra trás. No início, eu achava que eram eles que tinham me abandonado. E hoje eu acho que fui eu que abandonei eles".

A tendência ao isolamento é grande, em geral parecendo ao enlutado que são os outros que o estão ignorando porque não podem lidar com a sua dor. O afastamento da família e dos amigos costuma ocorrer já que, aparentemente, a convivência com eles exacerba a dor por rememorar a época em que o filho estava vivo.

Contudo, chamamos a atenção do leitor para algo que contradiz tudo o que foi dito até o momento e que aparece no filme. Trata-se do fato surpreendente de Becca desejar aproximar-se daquele que está mais próximo do evento da perda e que causou a morte de seu filho. Como, a partir da Psicanálise, poderíamos compreender essa atitude de Becca? Férenczi dispõe de uma teoria que versa sobre a possibilidade de uma identificação com o agressor, a qual apresentaremos a seguir, com o intuito de lançar luz a essa questão de teor tão enigmático ao espectador do filme.

f) Identificação da mãe com o agressor
Becca passa a desejar e a insistir em estar na presença do adolescente evitando ser vista e, quando toma coragem, convida-o a encontrarse com ela para conversarem. Depois desse primeiro encontro em que conversam sobre o evento da morte de Danny eles passam a se ver com frequência. Ao que parece, Becca desenvolve um afeto maternal por Jason e tenta agradá-lo e participar cada vez mais de sua vida. Todo o desenrolar das cenas de Becca com Jason indica que ela fez uma identificação com aquele que matou seu filho.

A partir da teoria de Ferenczi a respeito do trauma desestruturante, que ocorre em dois tempos, e admitindo que o evento da perda do filho tenha sido algo traumático para Becca, podemos entender o processo de identificação que ela faz com o assassino do filho. Férenczi (1966) explica que, em um segundo tempo do trauma - nesse caso, o tempo em que Becca reencontra Jason, após o primeiro tempo em que ele atropela seu filho -, a realidade insiste em mostrar para a vítima que o dado trágico é incontestável. O reencontro com Jason reafirma definitivamente a ausência e a morte de seu filho. O trauma que se instaura nesse reencontro é tão desestruturante que para Becca não resta mais nada a não ser identificar-se com o "agressor". Férenczi (1966) afirma que o segundo tempo do trauma faz com que a vítima se cale e com que atinja o máximo grau de ansiedade, de forma que passa a esquecer-se de si mesma e fantasia ser o desejo do agressor, identificando-se com ele (Férenczi, 1966).

Diante da identificação com o agressor, esse deixa de fazer parte da realidade externa e passa a fazer parte da realidade interna da vítima. Esse movimento em que o agressor passa existir para a vítima intrapsiquicamente é denominado de "introjeção". Por se configurar uma realidade intrapsíquica, a vítima consegue remodelar os acontecimentos violentos, quaisquer que sejam, de maneira alucinatória, positiva ou negativamente, pois não se trata mais de algo extrapsíquico e solidificado. Dessa forma, no curso do transe traumático, torna-se possível para a vítima desenvolver certa ternura pelo agressor (Férenczi, 1966).

A ternura que Becca desenvolve por Jason a coloca em "maus lençóis" com Howie quando 
ele descobre que ela se encontrava com o garoto para conversar. A reação de Howie é de extrema agressividade contra Jason, visto que não faz a mesma identificação com ele.

Parece que Becca consegue dissolver essa relação com Jason quando vê que ele está se formando e que em breve estará deixando a cidade; deixando-a como Danny a deixou. No momento em que Becca parece dar-se conta disso, ela começa a chorar desesperadamente, sentindo mais uma vez a dor da perda. Contudo, é essa fragilidade em que ela adentra que permite um "reencontro" com o marido e a busca por uma possibilidade compartilhada de sobrevivência à perda do filho.

A questão enigmática retratada nesse tópico dá abertura a outras interrogações que clamam por mais escuta e pesquisa: por que Becca não sente raiva de Jason? Por que ela desenvolve uma maternagem com ele? O que isso tem a ver com o sentimento ambivalente de Becca de passar a "amar" aquele que matou seu filho?

Uma possibilidade para pensar essas questões é pela via da própria identificação. Na medida em que abrimos hipótese de uma identificação ter sido feita com Jason, estamos lidando com uma ferida de ordem narcísica que está "tapada" por esse mecanismo ${ }^{6}$. No momento em que Jason termina o colegial e que fica claro que ele também deixará de fazer parte da vida de Becca, ela finalmente entra em contato com a devastadora dor da perda, mostrando-se frágil. É nesse momento que ela adentra num processo juntamente com o marido, que parece dizer de um luto.

6 Podemos observar esse acontecimento em diversas situações de violência, como na Síndrome de Estocolmo, na qual a vítima simpatiza e se identifica com o agressor, chegando a defendê-lo de acusações publicamente.
Contudo, como de costume, um trabalho psicanalítico que tem início com uma ou algumas questões centrais termina com mais questões em aberto do que com respostas. As perguntas que acabamos de expor e que deixamos em aberto a outras interpretações estão aí para indicar a complexidade do tema retratado e a possibilidade de continuidade e aprofundamento do trabalho.

\section{Considerações finais}

A realização da proposta do presente trabalho deixa clara a importância de tentar compreender do que se tratam as reações à perda de um ente querido quando o investimento libidinal realizado é intenso, como o dos pais para os filhos. Diversas reações e atos diante da perda fazem pontos de interrogações à Psicologia, que deve se ocupar dessas questões visando desenvolver uma postura, bem como intervenções mais voltadas ao sofrimento relativo à perda dos objetos amados.

As falas das mães que perderam filhos apresentadas neste artigo carregam consigo o peso de uma perda devastadora. O trabalho clínico com essas mães remete a uma especificidade, principalmente quando se constata que o vínculo estabelecido entre mãe e filho é de ordem narcísica. A magnitude do sofrimento é soberana, pois é como se a mãe perdesse literalmente um pedaço de si.

O trabalho com essas mães mostra que não há tempo que baste para a elaboração da perda. A dor é infindável. Parece não haver elaboração possível, tendo em vista que um filho não é objeto substituível. Percebe-se, inclusive, uma acentuada dificuldade de as mães aceitarem que seus filhos morreram. Diante dessa situação, acabam por desenvolver mecanismos de defesa como, por exemplo, recorrer ao pensamento de que o filho está apenas viajando e incomunicável no local onde está hospedado.

A perda do filho abre um buraco, uma grande ferida narcísica que afunda as mães em severos quadros melancólicos. Nos primeiros tempos, elas não querem sair da cama nem mesmo para comer ou tomar banho.

O papel da Psicanálise trata de conceder um lugar de sofrimento para a mãe que perde o filho sem, contudo, deixar que ela recaia completamente no lugar de vítima, para que possa fazer um "giro" da morte em direção à vida.

Para isso, parece ser necessário um manejo de muita paciência, mas também de cortes, pois a tendência das pacientes costuma ser envolver o analista em sua trama melancólica e convencê-lo de que nada pode ser feito. Trata-se de um trabalho difícil, de longo prazo e que envolve a difícil escuta de falas 
constantes acerca da morte, da decomposição, da violência etc.

Sabemos que o culto ao morto vem perdendo espaço na sociedade. Os velórios estão mais curtos, o tempo de enlutamento diminuiu e as pessoas não aguentam ouvir as histórias sobre o morto. Na contramão dessa tendência, é possível afirmar que este trabalho possibilitou-nos pensar a questão do luto e da perda a partir de mais um subsídio - o filme -, que além de ser bastante fiel ao que se observa clinicamente na realidade, é um material acessível à comunidade, o que é interessante no sentido de permitir que as pessoas entrem em contato com esse tema que é de todos mas que é cotidiana e convenientemente apagado de nossas vidas. 


\section{Maria Virginia Filomena Cremasco}

Psicóloga. Psicanalista. Doutora em Saúde Mental (Unicamp, 2002) e pós-doutorado em Psicopatologia e Psicanálise (Université Paris VII, 2010). Diretora do Laboratório de Psicopatologia Fundamental da UFPR (CNPq). Organizadora, dentre outros, dos livros Trauma, Traços e Memória pela Editora CRV, 2013 e Solidarity,Memory and Identity pela Cambridge Editors, 2015. Professora Associada do Departamento e do Mestrado em Psicologia da Universidade Federal do Paraná, Curitiba - PR. Brasil.

E-mail: mavicremasco@hotmail.com

\section{Dhyone Schinemann*}

Psicólogo formado pela Universidade Estadual do Centro Oeste (2009). Trabalha com a clínica psicanalítica em consultório particular. Mestre em Psicologia Clínica no Programa de Mestrado em Psicologia da Universidade Federal do Paraná (2014), Curitiba - PR. Brasil. *Bolsista da CAPES - Brasil. E-mail: dhyonesch@hotmail.com

\section{Susana de Oliveira Pimenta*}

Psicóloga formada pela Universidade Federal do Paraná (2011). Trabalha com a clínica psicanalítica em consultório particular. Mestre em Psicologia Clínica no Programa de Mestrado em Psicologia da Universidade Federal do Paraná (2014), Curitiba - PR. Brasil.

*Bolsista da CAPES - Brasil. E-mail: suoliveirapimenta@gmail.com

Endereço para envio de correspondência:

Universidade Federal do Paraná, Praça Santos Andrade, 50, sala 211. Centro.

CEP 80060-240 - Curitiba - PR. Brasil.

Recebido 13/11/2013, Aprovado 27/11/2014. 
Referências

Férenczi, S. (1966). La confusión de lenguajes entre los adultos y el niño. In S. Férenczi, Problemas y métodos del psicoanálisis. Buenos Aires: Ediciones Horme S.A.E. (Trabalho original publicado em 1933).

Freud, S. (1996a). Análise Terminável e Interminável. In S. Freud, Edição standard brasileira das obras psicológicas completas de Sigmund Freud (J. Salomão, trad., Vol. 23, pp. 225-274). Rio de Janeiro: Imago. (Trabalho original publicado em 1937).

Freud, S. (1996b). Novas conferências introdutórias sobre Psicanálise: Conferência XXXIII: Feminilidade. In S. Freud, Edição standard brasileira das obras psicológicas completas de Sigmund Freud (J. Salomão, trad., Vol. 22, pp. 113-134). Rio de Janeiro: Imago. (Trabalho original publicado em 1933).

Freud, S. (1996c). Alguns tipos de caráter encontrados no trabalho psicanalítico. In S. Freud, Edição standard brasileira das obras psicológicas completas de Sigmund Freud (J. Salomão, trad., Vol. 14, pp. 325-350). Rio de Janeiro: Imago. (Trabalho original publicado em 1916).

Freud, S. (1996d). Conferências introdutórias sobre Psicanálise: Conferência XXVI. In S. Freud, Edição standard brasileira das obras psicológicas completas de Sigmund Freud (J. Salomão, trad., Vol. 16, pp. 413-432). Rio de Janeiro: Imago. (Trabalho original publicado em 1917).

Freud, S. (1996e). Luto e melancolia. In S. Freud, Edição standard brasileira das obras psicológicas completas de Sigmund Freud (J. Salomão, trad., Vol. 14, pp. 245-270). Rio de Janeiro: Imago. (Trabalho original publicado em 1917).

Freud, S. (1996f). Reflexões para os tempos de guerra e morte. In S. Freud, Edição standard brasileira das obras psicológicas completas de Sigmund Freud (J. Salomão, trad., Vol. 14, pp. 285-316). Rio de Janeiro: Imago. (Trabalho original publicado em 1915).

Freud, S. (1996g). Sobre o narcisismo: uma introdução. In S. Freud, Edição standard brasileira das obras psicológicas completas de Sigmund Freud (J. Salomão, trad., Vol. 14, pp. 77-110). Rio de Janeiro: Imago. (Trabalho original publicado em 1914).

Freud, S. (1996h). Totem e tabu. In S. Freud, Edição standard brasileira das obras psicológicas completas de Sigmund Freud (J. Salomão, trad., Vol. 13, pp. 13-168). Rio de Janeiro: Imago. (Trabalho original publicado em 1913).

Freud, S. (1996i). Sonhos sobre a morte de pessoas queridas. In S. Freud, Edição standard brasileira das obras psicológicas completas de Sigmund Freud (J. Salomão, trad., Vol. 4, pp. 276-297). Rio de Janeiro: Imago. (Trabalho original publicado em 1900).

Universidade Federal de Minas Gerais - UFMG. Observatório Astronômico Frei Rosário. Viagens no tempo, túneis no espaço e suas implicações na história da humanindade. Belo Horizonte. Recuperado em 7 de julho de 2013, de http:// www.observatorio.ufmg.br/pas68.htm 